\title{
Robotic enucleation for pediatric insulinoma with MEN1 syndrome: a case report and literature review
}

\author{
Mei Liang ${ }^{1 \dagger}$, Jialin Jiang ${ }^{2 \dagger}$, Hongmei Dai ${ }^{2 \dagger}$, Xiafei Hong ${ }^{1}$, Xianlin Han² ${ }^{2}$ Lin Cong ${ }^{2}$, Anli Tong ${ }^{3}$, Fang Li ${ }^{4}$, Yaping Luo ${ }^{4}$, \\ Weinan Liu ${ }^{2}$, Liangrui Zhou ${ }^{5}$, Wenyu $\mathrm{Di}^{6}$, Wenming $\mathrm{Wu}^{2^{*}}$ and Yupei Zhao ${ }^{2^{*}}$
}

\begin{abstract}
Background: A patient with a rare pediatric insulinoma and MEN1 syndrome was treated by robotic enucleation surgery.

Case presentation: We present a case of a 9-year-old girl presenting with repeated loss of consciousness, concomitant with a pale face, palpitations, and convulsions, which had persisted for 2 years and had been aggravated during the previous 2 months. She was previously misdiagnosed with epilepsy in another hospital. We further examined her while she was hospitalized. By combining her medical history and imaging examination and lab test results, a diagnosis of insulinoma was confirmed. Sanger-directed sequencing on a peripheral blood sample revealed an MEN1 gene mutation, indicating pediatric insulinoma with MEN1 syndrome. The patient underwent minimally invasive insulinoma enucleation surgery under the Da Vinci robot-assisted system with intraoperative ultrasound (IOUS) connected. The surgery was successfully completed within $65 \mathrm{~min}$, and the girl recovered well postoperatively and no longer experienced symptoms of hypoglycemia.
\end{abstract}

Conclusion: This is the first report of a case of pediatric insulinoma treated using robotic enucleation. This experience demonstrates the feasibility and safety of combining robotic surgery with the enucleation procedure as an excellent strategy for pediatric insulinoma.

Keywords: Pediatric insulinoma, Robotic enucleation, MEN1 syndrome, Surgery

\section{Background}

Insulinomas are insulin-secreting pancreatic neuroendocrine tumors (pNETs) that affect an estimated 1 in 250,000 people per year. The median age of patients at presentation is approximately 47 years, and insulinomas seldom occur in pediatric patients [1]. Due to excess insulin secretion, patients with insulinomas have recurrent hypoglycemia. Such patients usually present with Whipple's triad, which consists of hypoglycemia, neuroglycopenic symptoms, and symptom relief with glucose administration. Nearly $10 \%$ of insulinomas occur in the context of MEN1, an autosomal dominant

\footnotetext{
*Correspondence: doctorwuu@126.com; zhao8028@263.net

${ }^{+}$Mei Liang, Jialin Jiang and Hongmei Dai contributed equally to this work.

2Department of General Surgery, Peking Union Medical College Hospital,

Chinese Academy of Medical Science \& Peking Union Medical College,

Beijing, China

Full list of author information is available at the end of the article
}

disorder. More than 1300 mutations in MEN1 have been reported, and most of these mutations likely disrupt the interactions of the menin protein with other proteins, thus altering critical events in cell cycle regulation and proliferation [2]. Additionally, MEN1 mutations are more common in insulinomas in children than in adults [3]. Diagnoses of insulinoma can be challenging because of the presence of nonspecific symptoms. Surgical resection is the best choice for most patients. In this paper, we describe a patient with pediatric insulinoma and MEN1 syndrome. Traditionally, open surgery has been the main surgical choice for such a pediatric patient. Recently, minimally invasive surgery has been adopted to treat insulinoma. Ming-Gen et al. recently used robotic spleen-preserving distal pancreatectomy to treat pediatric insulinoma [4]. Our surgical center was the first to report a study on robotic enucleation for small pancreatic

(c) The Author(s). 2018 Open Access This article is distributed under the terms of the Creative Commons Attribution 4.0 International License (http://creativecommons.org/licenses/by/4.0/), which permits unrestricted use, distribution, and reproduction in any medium, provided you give appropriate credit to the original author(s) and the source, provide a link to the Creative Commons license, and indicate if changes were made. The Creative Commons Public Domain Dedication waiver (http://creativecommons.org/publicdomain/zero/1.0/) applies to the data made available in this article, unless otherwise stated. 
neuroendocrine tumors in adults [5]. Here, we present robotic enucleation for a pediatric insulinoma patient with MEN1 syndrome. To the best of our knowledge, this is the first reported robotic enucleation surgery for pediatric insulinoma.

\section{Case presentation}

A 9-year-old girl was admitted due to repeated loss of consciousness, concomitant with a pale face, palpitations, and convulsions, which had persisted for 2 years and had been aggravated during the previous 2 months. These symptoms occurred automatically. The patient denied experiencing any sweating, nausea, vomiting, trembling, or an obvious sense of hunger before meals. The patient was previously misdiagnosed with epilepsy in another hospital, but no abnormal findings were detected on a 24-h electroencephalogram at our hospital. Her abdominal perfusion CT showed a highly perfused nodule within the pancreatic tail; A magnetic resonance scan confirmed the location of this nodule and indicated that its size was $11.6 \times 13.2 \mathrm{~mm}$ (Fig. 1a-f). Additionally, ${ }^{68} \mathrm{Ga}$-exendin 4 PET-CT showed a region in the pancreatic tail with abnormally high metabolism and overexpression of the glucagon-like peptide-1 receptor (Fig. 1g-i). Lab testing showed a low fasting blood glucose (BG) of $2.2 \mathrm{mmol} / \mathrm{L}$ (reference range: $3.9-6.1 \mathrm{mmol} / \mathrm{L}$ ), a high proinsulin level of $4455.9 \mathrm{pg} / \mathrm{mL}$ (reference range: $30-180 \mathrm{ng} / \mathrm{mL}$ ), a normal C-peptide level of $2.56 \mathrm{ng} / \mathrm{mL}$ (reference range:
$0.8-4.2 \mathrm{ng} / \mathrm{mL}$ ), a serum insulin level of $15.35 \mu \mathrm{IU} / \mathrm{mL}$ (reference range: $5.2-17.2 \mu \mathrm{IU} / \mathrm{mL}$ ), and a gastrin level of $92.6 \mathrm{pg} / \mathrm{mL}$ (reference range: $<100 \mathrm{pg} / \mathrm{mL}$ ). These results confirmed a diagnosis of insulinoma. Imaging examination showed no abnormalities indicative of parathyroid adenoma or malignancy in the pituitary or adrenal glands. Lab testing showed normal levels of parathyroid hormone $(\mathrm{PTH})$, blood calcium, phosphate, follicle-stimulating hormone $(\mathrm{FSH})$, growth hormone $(\mathrm{GH})$, prolactin (PRL), adrenocorticotropic hormone $(\mathrm{ACTH}), 24$-h urinary free cortisol (24 hUFC), and serum cortisol. Her luteinizing hormone (LH) level was $0.24 \mathrm{IU} / \mathrm{L}$ (reference range: $2.12-$ $10 \mathrm{IU} / \mathrm{L}$ during the follicular phase), which was considered related to her age.

Preoperative preparation: To avoid recurrent symptoms and to maintain her fasting BG at a tolerably low level, the patient was given regular snacks before bedtime. BG can be controlled at a level between 50 and $60 \mathrm{mg} / \mathrm{dL}$ preoperatively.

Surgical procedure: The patient underwent minimally invasive insulinoma enucleation surgery under the $\mathrm{Da}$ Vinci robot-assisted system with intraoperative ultrasound (IOUS) connected. The patient was put in a head-low, feet-high and left-lateral position. The robotic system was positioned at the head of the patient, while the assistant surgeon stood between the patient's legs. Abdominal exploration via laparoscopy was conducted, and no obvious abnormalities were found. The robotic
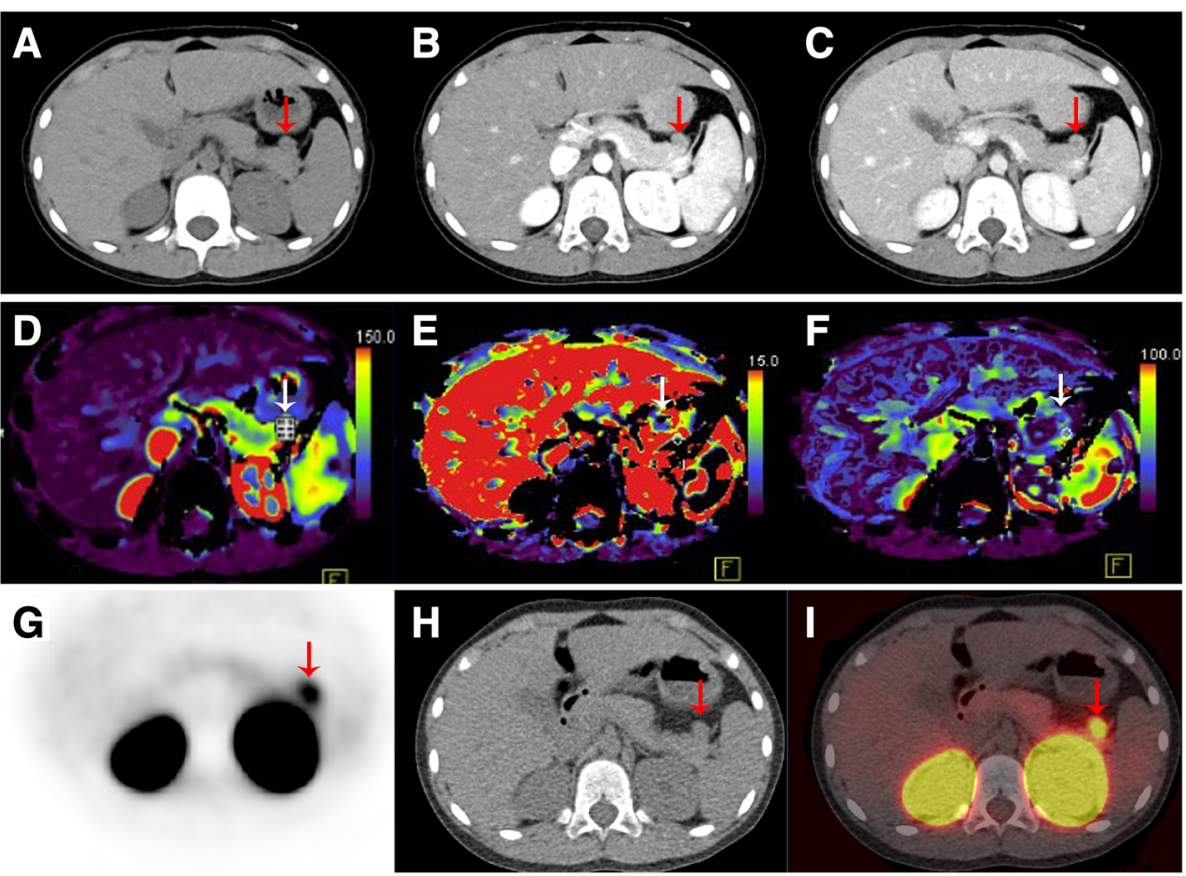

Fig. $1 \mathrm{CT}$ and ${ }^{68} \mathrm{Ga}$-exendin-4 PET-CT scan of the pancreas. The tumor is marked with asterisks. a Non-enhanced phase scan. b Arterial phase. c Portal phase. $\mathbf{d}$-f Pancreatic perfusion imaging. $\mathbf{g}-\mathbf{i}{ }^{68} \mathrm{Ga}$-exendin-4 PET-CT scan of the pancreas 
lens and operating arms were docked. The gastrocolic ligament was dissected with an ultrasonically activated scalpel. The head of the pancreas was exposed by grasping the colon downward and lifting the stomach. Towards the tail of the pancreas, we separated and exposed the spleen. The surgeon then controlled the ultrasound probe, exploring the tumor from the pancreatic tail to the head and the uncinated process with the assistance of a prograsp clamp. A quasi-circular, hypoechoic lesion was found at the end of the pancreas with a diameter of approximately $10 \mathrm{~mm}$ and a clear boundary. We marked the normal pancreatic tissue around the lesion with an electrotome, and while dividing the pancreas sequentially, suction was used continually to visualize the tumor capsule. Precise positioning was achieved using IOUS, and the tumor was completely resected along the capsule (Fig. 2a-c). A peritoneal drainage tube was placed. The surgery went well, lasting $65 \mathrm{~min}$ (skin to skin), and the volume of intraoperative bleeding was $5 \mathrm{~mL}$. Intraoperative BG is documented in Table 1 .

After surgery, the patient was given liquid diet on POD2. The drain was clean and was removed on POD4, and the patient gradually resumed her normal diet. She was discharged to home on POD6. During the following 1.5 years, the patient had no recurrence of the disease.
No postoperative complication occurred, such as pancreatic fistula or pancreatic function deficiency.

Pathological examination showed that the tumor was a pancreatic neuroendocrine tumor (Grade 2 with a Ki-67 index of 4\%) (Fig. 2d-e). This tumor was positive for CgA, Syn, and AE1/AE3 (Fig. 2f-h). Insulin staining was partially positive (Fig. 2i), while gastrin, glucagon, and somatostatin staining were negative (Fig. 2j-1).

Sanger-directed sequencing for the MEN1 gene mutation was performed on a peripheral blood sample, revealing a homozygous pathogenic mutation of c247_250delCTGT (p.Ile85Serfs"33) (Fig. 3). This point mutation was also detected in the frozen tissue of the patient.

\section{Discussion and conclusion}

Insulinoma is the most common type of pNET, and such tumors seldom occur in pediatric patients [6]. Recently, we searched all of the literature regarding pediatric insulinoma from the past 10 years and summarized the characteristics of 65 cases in 16 studies (Table 2) [4, 7-21].

Among the cases in the past decade that we reviewed, distal pancreatectomy and pancreaticoduodenectomy were the most common therapeutic procedures. Only 4 enucleations were performed, including 3 open and 1 laparoscopic. Notably, one patient underwent robotic
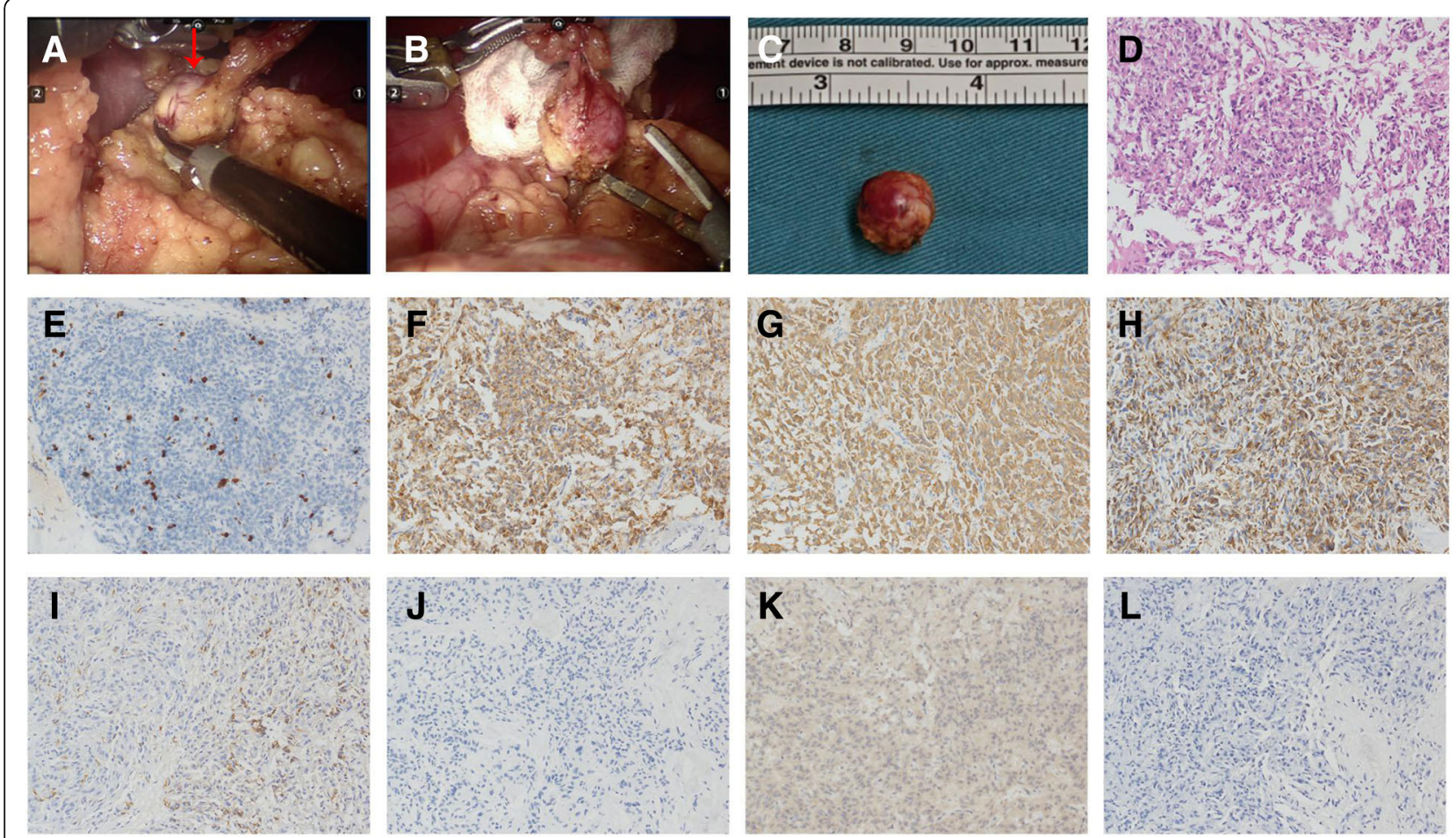

Fig. 2 Surgical and pathology images of the tumor. a-b: Surgical photographs of pancreatic tumor enucleation. c: Gross view of the tumor. $\mathbf{d}-\mathbf{e}$ : $\mathrm{HE}$ and Ki-67 staining, which showed that the pancreatic neuroendocrine tumor was of Grade 2 with a Ki-67 index of 4\%. f-h: CgA, Syn, and AE1/AE3 staining were positive, which confirmed that the tumor was derived from neuroendocrine cells. i: Insulin staining was partially positive. j-l: Glucagon, gastrin and somatostatin staining were negetive 
Table 1 Intraoperative blood glucose monitoring

\begin{tabular}{ll}
\hline Time (minutes) & Blood Glucose $(\mathrm{mg} / \mathrm{dL})$ \\
\hline Prior to tumor removal & 59.4 \\
Immediately following removal of the tumor & 68 \\
15 min after tumor resection & 82.8 \\
30 min after tumor resection & 90 \\
40 min after tumor resection & 75.6 \\
60 min after tumor resection & 90 \\
\hline
\end{tabular}

distal pancreatectomy in 2017, which was the first application of a robotic surgery system in pediatric insulinoma treatment.

Imaging examination is an essential step for preoperative confirmation and localization of an insulinoma. In our case, we used two advanced methods for localization which have improved the accuracy of diagnosis significantly: ${ }^{68} \mathrm{Ga}$-DOTANOC PET/CT and laparoscopic ultrasound (LUS). An examination of pNET diagnosis and staging data from 141 patients indicated that the overall sensitivity, specificity, and accuracy of ${ }^{68} \mathrm{Ga}$-DOTANOC $\mathrm{PET} / \mathrm{CT}$ for diagnosing patients with pancreatic neuroendocrine tumors were $85.7,79.1$, and $84.8 \%$, respectively [22]. Meanwhile, in a study by Li et al., intraoperative LUS alone detected all insulinoma tumors with $100 \%$ sensitivity and $100 \%$ specificity [23].

In the past, pancreaticoduodenectomy and pancreatectomy have generally been the standard operative procedures for benign and borderline pancreatic tumors, but they seem excessive because of the increased risk of postoperative endocrine and exocrine insufficiency owing to wide resection of the pancreatic parenchyma. Patients undergoing partial resection had a higher rate of new postoperative diabetes and more use of pancreatic enzymes postoperatively than those who receiving pancreatic enucleation [24] .

Therefore, enucleation appears to be a better option as an effective therapeutic procedure for such tumors, allowing preservation of long-term pancreatic function while achieving favorable oncological outcomes [25]. Previous reports have shown that enucleation allows a more limited excision extent, thus offering several advantages in terms of function conservation, blood loss and surgical time [26], all of which are especially important for children whose normal parenchyma is still developing. Additionally, many studies have confirmed the low recurrence rate after enucleation of benign or low-grade malignant tumors. No significant difference is evident in prognosis of patients with insulinoma between groups of enucleation and partial pancreatic resection [27].

Specific indications for pancreatic tumor enucleation are as follows: benign, isolated lesions with a distance between the tumor and the main pancreatic duct $\geq 3 \mathrm{~mm}$ (no focal stricture or dilation), insulinomas, gastrinomas $<2 \mathrm{~cm}$, and nonfunctional pancreatic neuroendocrine tumors (NF-pNETs) $<1-2 \mathrm{~cm}$ with a low Ki67 mitotic index [28]. Insulinomas $<2 \mathrm{~cm}$ are ideal candidates for enucleation, especially considering their $80 \%$ probability of being benign [28].

The Da Vinci Surgical System enables robot-assisted surgery, which provides surgeons with a three-dimensional view, high articulation ability, scaling functions, filtering functions to avoid shaking, and visual magnification. When it comes to pancreatic surgery, several studies have reported the advantages of robotic approach over conventional laparoscopic means, such as less rate of conversion to laparotomy, less blood loss and shorter postoperative hospital stay [29, 30]. However, enucleation of pNETs via robotic surgery has been described only a few times worldwide. Recently, our surgical center reported that robotic surgery for enucleation of pNETs smaller than $2 \mathrm{~cm}$ did not increase postoperative pancreatic fistula (POPF) or major complication rates and reduced the duration of surgery and estimated blood loss when compared with open surgery [5]. ,Robotic enucleation provides the dual benefits of minimal invasiveness and good pancreatic parenchymal conservation. Notably, for children, considering their

\section{c.247_250delCTGT, p.Ile85Serfs*33}

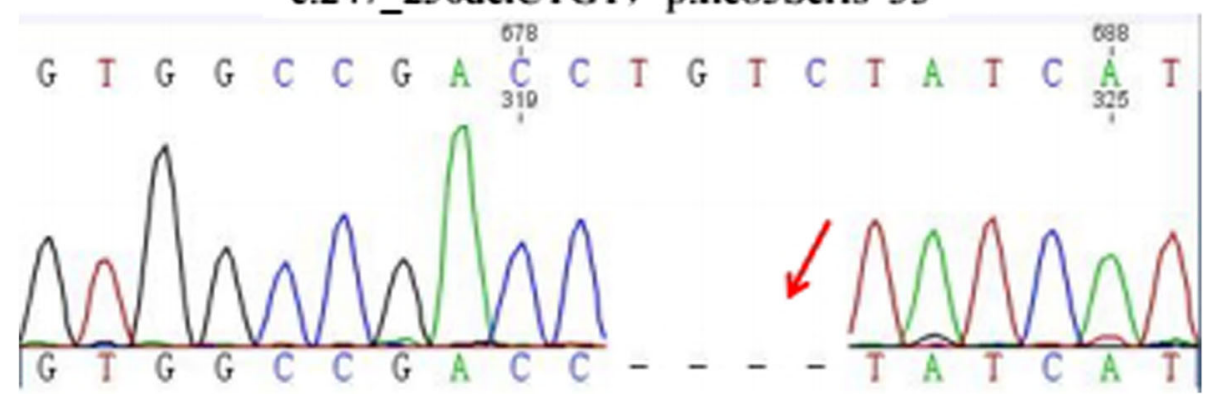

Fig. 3 Sequence analysis of the MEN1 gene revealed a homozygous frameshift for c.247_250delCTGT(p.lle85Serfs*33). This point mutation was detected both in the blood sample and frozen tissue of the patient 


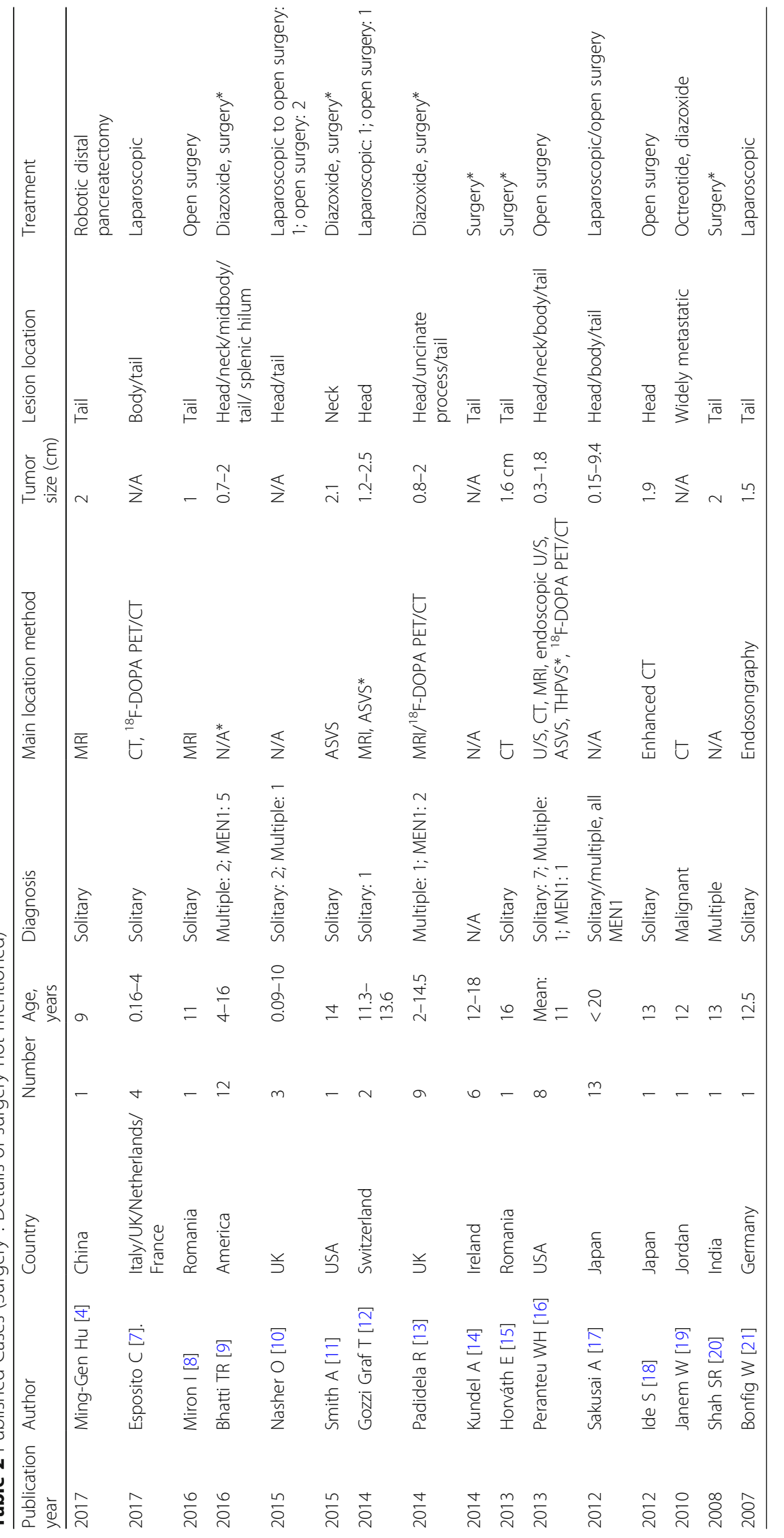


poor tolerability for operative trauma and anesthesia, demands for a faster and less traumatic surgical procedure are increasing. Therefore, robotic enucleation is considered an ideal strategy for pediatric insulinomas meeting the operative indications.

This is the first case of pediatric insulinoma treated via robotic enucleation in the world. The operation was completed in $65 \mathrm{~min}$ (skin to skin) with only $5 \mathrm{~mL}$ of blood loss. No POPF occurred after surgery. The patient recovered well and was discharged home on POD 6. During the following 1.5 years, she had no recurrence of the disease nor experienced her previous symptoms of hypoglycemia. No postoperative complication occurred, such as pancreatic fistula or pancreatic function deficiency. This experience has demonstrated the feasibility and safety of the robotic enucleation procedure, with an excellent curative effect for pediatric insulinoma.

\section{Abbreviations}

ASVS: Selective arterial calcium stimulation and hepatic venous sampling of insulin; MEN1: Multiple endocrine neoplasia type 1; N/A: Data not available; PET-CT: Positron Emission Tomography-Computed Tomography; POD: Postoperative day; POPF: Increase postoperative pancreatic fistula; THPVS: Transhepatic portal venous sampling

\section{Acknowledgements}

We thank Dr. Dandan Hu from the Chinese Academy of Medical Science \& Peking Union Medical College and Xue Sun from the Department of Special Medicine of Beijing Hospital for their great contributions to the manuscript.

\section{Funding}

This work was supported by grants from The National Natural Science Foundation of China (81573009 and 81603157), Preeminent Youth Fund of Peking Union Medical College Hospital (JQ201507), Youth Fund of Peking Union Medical College Hospital (pumch-2016-2.22), and Chinese Academy of Medical Sciences Initiative for Innovative Medicine (2017-12 M-1-001).

\section{Availability of data and materials}

The data supporting the findings of this study are available from Peking Union Medical College Hospital, but restrictions apply to the availability of these data, which were used under license for the current study and are not publicly available. However, the data are available from the authors upon reasonable request and with permission from Peking Union Medical College Hospital.

\section{Authors' contributions \\ $M L, J$ and $H D$ contributed equally to this article. $W W, Y Z, M L, J J$, and $X H$ conceived and designed the work. LC, AT, FL, YL, WL, and LZ contributed to the data collection. ML, JJ and HD drafted the manuscript. XH, AT, and WD revised the manuscript critically for important intellectual content and provided comments on the structure, details and grammar of the article. All authors read and approved the final manuscript.}

\section{Ethics approval and consent to participate}

This study has been approved by the Institutional Ethics Committee of PUMCH, Chinese Academy of Medical Sciences and conforms to the principles expressed in the Declaration of Helsinki.

\section{Consent for publication}

Written informed consent was obtained from the patient and her legal guardians for publication of this case report and any accompanying images.

\section{Competing interests}

The authors declare that they have no competing interests.

\section{Publisher's Note}

Springer Nature remains neutral with regard to jurisdictional claims in published maps and institutional affiliations.

\section{Author details}

'Department of Surgery, Peking Union Medical College Hospital, Chinese Academy of Medical Science \& Peking Union Medical College, Beijing, China. ${ }^{2}$ Department of General Surgery, Peking Union Medical College Hospital, Chinese Academy of Medical Science \& Peking Union Medical College, Beijing, China. ${ }^{3}$ Department of Endocrinology, Peking Union Medical College Hospital, Chinese Academy of Medical Science \& Peking Union Medical College, Beijing, China. ${ }^{4}$ Department of Neurology, Peking Union Medical College Hospital, Chinese Academy of Medical Science \& Peking Union Medical College, Beijing, China. ${ }^{5}$ Department of Pathology, Peking Union Medical College Hospital, Chinese Academy of Medical Science \& Peking Union Medical College, Beijing, China. ${ }^{6}$ Department of Pathology, The First Affiliated Hospital of Xinxiang Medical University, Weihui, China.

Received: 8 February 2018 Accepted: 11 June 2018

Published online: 19 June 2018

\section{References}

1. Vaidakis D, Karoubalis J, Pappa T, Piaditis G, Zografos GN. Pancreatic insulinoma: current issues and trends. Hepatobiliary Pancreat Dis Int. 2010; 9(3):234-41. Review

2. Thakker RV. Multiple endocrine neoplasia type 1 (MEN1). Best Pract Res Clin Endocrinol Metab. 2010;24(3):355-70.

3. Sakurai A, Yamazaki, M, Suzuki S, Fukushima T, Imai T, Kikumori T, Okamoto T, Horiuchi K, Uchino S, Kosugi S, Yamada M, Komoto I, Hanazaki K, Itoh M, Kondo T, Mihara M, Imamura M. Clinical features of insulinoma in patients with multiple endocrine neoplasia type 1: analysis of the database of the MEN Consortium of Japan. Endocrine Journal. 2012;59(10):859-66.

4. Hu MG, Xiao YH, Song DD, Zhao GD, Liu YZ, Wang Z, Li HY, Liu R. First experience of robotic spleen-preserving distal pancreatectomy in a child with insulinoma. World J Surg Oncol. 2017;15(1):199.

5. Tian F, Hong, X. F, Wu W. M, Han X. L, Wang M. Y, Cong L, Dai M. H, Liao Q, Zhang T. P, Zhao Y. P. Propensity score-matched analysis of robotic versus open surgical enucleation for small pancreatic neuroendocrine tumours. $\mathrm{Br}$ J Surg 2016;103(10):1358-1364.

6. Padidela R. Insulinoma in childhood: clinical, radiological, molecular and histological aspects of nine patients. Eur J Endocrinol. 2014;170:741-7.

7. Esposito C, De Lagausie P, Escolino M, Saxena A, Holcomb G. W, Settimi A, Becmeur F, van der Zee D. Laparoscopic Resection of Pancreatic Tumors in Children: Results of a Multicentric Survey. J Laparoendosc Adv Surg Tech A 2017 27(5): 533-538.

8. Miron I, Diaconescu S, Aprodu G, Ioniuc I, Diaconescu MR, Miron L. Diagnostic difficulties in a pediatric Insulinoma: a case report. Medicine (Baltimore). 2016;95(11):e3045.

9. Bhatti TR, Ganapathy K, Huppmann AR, Conlin L, Boodhansingh KE, MacMullen C, Becker S, Ernst LM, Adzick NS, Ruchelli ED, Ganguly A, Stanley CA. Histologic and molecular profile of pediatric Insulinomas: evidence of a paternal parent-of-origin effect. J Clin Endocrinol Metab. 2016;101(3):914-22.

10. Nasher O, Hall NJ, Sebire NJ, de Coppi P, Pierro A. Pancreatic tumours in children: diagnosis, treatment and outcome. Pediatr Surg Int. 2015;31(9):831-5.

11. Smith A, Thornton PS, Galliani CA, Miller JP, Dykes J, Leung-Pineda V. A 14year old girl with reversible hypoglycemic episodes: the role of ASVS. Pediatr Dev Pathol. 2015;18(1):80-3.

12. Gozzi Graf T, Brändle M, Clerici T, I'Allemand D. Insulinoma: only in adults?case reports and literature review. Eur J Pediatr 2014;173(5):567-574.

13. Padidela R, Fiest M, Arya V, Smith W, Ashworth M, Rampling D, Newbould M, Batra G, James J, Wright NB, Dunne MJ, Clayton PE, Banerjee I, Hussain K. Insulinoma in childhood: clinical, radiological, molecular and histological aspects of nine patients. Eur J Endocrinol. 2014;170(5):741-7.

14. Kundel A, Thompson GB, Richards ML, Qiu LX, Cai Y, Schwenk FW, Lteif AN, Pittock ST, Kumar S, Tebben PJ, Hay ID, Grant CS. Pediatric endocrine surgery: a 20-year experience at the Mayo Clinic. J Clin Endocrinol Metab. 2014;99(2):399-406.

15. Horváth E, Gozar H, Chira L, Dunca I, Kiss E, Pávai Z. Insulinoma diagnosed as drug-refractory epilepsy in an adolescent boy: a case report. Romanian J Morphol Embryol. 2013;54(4):1147-51. 
16. Peranteau WH, Palladino AA, Bhatti TR, Becker SA, States $L$, Stanley CA, Scott Adzick N. The surgical management of insulinomas in children[J]. J Pediatr Surg. 2013;48(12):2517.

17. Sakurai A, Yamazaki M, Suzuki S, Fukushima T, Imai T, Kikumori T, Okamoto T, Horiuchi K, Uchino S, Kosugi S, Yamada M, Komoto I, Hanazaki K, Itoh M, Kondo T, Mihara M, Imamura M. Clinical features of insulinoma in patients with multiple endocrine neoplasia type 1: analysis of the database of the MEN consortium of Japan. Endocr J. 2012;59(10):859-66.

18. Ide S, Uchida K, Inoue M, Koike Y, Otake K, Matsushita K, Hashimoto K,

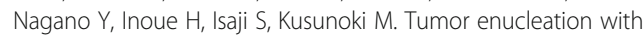
preoperative endoscopic transpapillary stenting for pediatric insulinoma. Pediatr Surg Int. 2012;28(7):707-9.

19. Janem W, Sultan I, Ajlouni F, Deebajeh R, Haddad H, Sughayer MA, Goussous RY. Malignant insulinoma in a child. Pediatr Blood Cancer. 2010:55(7):1423-6.

20. Shah SR, Raghavan R, Desai DC, Chauhan PH, Lala M, Dherai AJ, Ashavaid TF. An Indian family of multiple endocrine neoplasia type 1 (MEN1): molecular diagnosis. treatment and follow up Indian J Gastroenterol. 2008;27(6):242-4

21. Bonfig W, Kann P, Rothmund M, Schwarz HP. Recurrent hypoglycemic seizures and obesity: delayed diagnosis of an insulinoma in a 15 year-old boy-final diagnostic localization with endosonography. J Pediatr Endocrinol Metab. 2007;20(9):1035-8.

22. Sharma P, Arora S, Dhull VS, Naswa N, Kumar R, Ammini AC, Bal C. Evaluation of ${ }^{(68)} \mathrm{Ga}-\mathrm{DOTANOC}$ PET/CT imaging in a large exclusive population of pancreatic neuroendocrine tumors. Abdom Imaging. 2015; 40(2):299-309.

23. Li W, An L, Liu R, Yao K, Hu M, Zhao G, Tang J, Lv F. Laparoscopic ultrasound enhances diagnosis and localization of insulinoma in pancreatic head and neck for laparoscopic surgery with satisfactory postsurgical outcomes. Ultrasound Med Biol. 2011;37(7):1017-23.

24. Cauley CE, Pitt HA, Ziegler KM, Nakeeb A, Schmidt CM, Zyromski NJ, House MG, Lillemoe KD. Pancreatic enucleation: improved outcomes compared to resection. J Gastrointest Surg. 2012;16(7):1347-53.

25. Song K, Kim S, Hwang D, Lee J, Lee D, Lee J, Jun E, Sin S, Kim H, Park $K$, Lee $Y$. Enucleation for benign or low-grade malignant lesions of the pancreas: single-center experience with 65 consecutive patients. Surgery. 2015; 158(5):1203-10.

26. Wei J, Liu X, Wu J, Xu W, Gao W, Jiang K, Zhang Z, Miao Y. Diagnosis and surgical management of insulinomas in 33 consecutive patients at a single institution. Langenbeck's Arch Surg. 2016;401(7):1019-25.

27. Nikfarjam M, Warshaw AL, Axelrod L, Deshpande V, Thayer SP, Ferrone CR, Fernández-del Castillo C. Improved contemporary surgical management of insulinomas: a 25-year experience at the Massachusetts General Hospital. Ann Surg. 2008;247(1):165-72.

28. Ore A, Barrows C, Solis-Velasco M, Shaker J, Moser A. Robotic enucleation of benign pancreatic tumors. J Vis Surg. 2017;3:151.

29. Zhang J, Jin J, Chen S, Gu J, Zhu Y, Qin K, Zhan Q, Cheng D, Chen H, Deng $X$, Shen B, Peng C. Minimally invasive distal pancreatectomy for PNETs: laparoscopic or robotic approach? Oncotarget. 2017:8(20):33872-83.

30. Liu R, Liu Q, Zhao ZM, Tan XL, Gao YX, Zhao GD. Robotic versus laparoscopic distal pancreatectomy: a propensity score-matched study. J Surg Oncol. 2017;116(4):461-9.

\section{Ready to submit your research? Choose BMC and benefit from:}

- fast, convenient online submission

- thorough peer review by experienced researchers in your field

- rapid publication on acceptance

- support for research data, including large and complex data types

- gold Open Access which fosters wider collaboration and increased citations

- maximum visibility for your research: over $100 \mathrm{M}$ website views per year

At BMC, research is always in progress.

Learn more biomedcentral.com/submissions 